\title{
Acordo de Acionistas: Um Breve Estudo Acerca das Modalidades
}

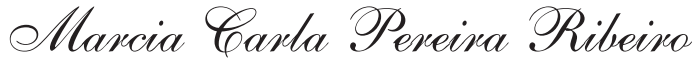

Mestre e Doutora em Direito, Professora de Direito Comercial da UFPR e PUCPR, em parceria e a partir de pesquisa realizada pelo acadêmico Luiz Daniel Haj Mussi, quarto ano do Curso de Direito da UFPR, Monitor da disciplina Direito Comercial A.

\section{SUMÁRIO}

Introdução;

1 Breve panorama do instituto no Direito brasileiro;

2 Natureza jurídica;

3 Modalidades de acordo; 3.1 Acordos sobre o exercício do direito a voto ou de poder de controle; 3.2 Acordos de bloqueio;

Conclusões;

Referências bibliográficas.

\section{Introdução ${ }^{1}$}

IV

a sistemática jurídica brasileira convivemos com o estabelecimento de modelos societários que guardam, entre si, características diferenciadoras, de forma a se adequarem às expectativas e necessidades dos empreendedores. Dentre as sociedades de responsabilidade limitada dos sócios, as sociedades anônimas representam, já no campo teórico, o modelo jurídico mais apropriado ao empreendimento de grande porte.

Em decorrência de poderem servir de modelo à grande empresa nacional, e ainda por serem o único modelo de sociedade que trabalha diretamente com a captação de recursos no mercado, na forma de oferta de ações para aquisição pública, as diversas mudanças que se impõem ao cenário econômico nacional repercutem diretamente na estrutura da sociedade por ações.

$\bigcirc$ desencadeamento do processo de inserção do Brasil na onda de interna-

1 O presente estudo foi elaborado em homenagem ao Professor CELSO BARBI FILHO. 
cionalização da economia conduziu a uma série de adaptações relativamente aos agentes econômicos, às sociedades comerciais, muito especialmente em sua modalidade por ações, de forma a adaptá-los às novas necessidades decorrentes da ascensão da competitividade como elemento essencial ao desenvolvimento econômico e manutenção das empresas no mercado que se pretende globalizado.

No campo da atuação do Estado na economia, desde 1990 uma onda de privatizações, incorporações, cisões e fusões foram intentadas, de forma a atingir uma reestruturação em busca de melhores resultados. A fim de facilitar as operações postas em prática, sobretudo no âmbito da desestatização das empresas federais, a Lei das Sociedades Anônimas ${ }^{2}$ foi modificada em 1997.3 Para viabilizar operações de reestruturação, como a cisão societária, o direito de retirada dos minoritários foi afastado e a sistemática de cálculo de sua indenização introduziu a noção de valor econômico. $\bigcirc$ saldo das alterações pode ser apurado num evidente retrocesso na garantia dos direitos das minorias.

No entanto, o propósito de desenvolvimento econômico do país, por meio de seu agente Sociedade Comercial, não pode prescindir da participação efetiva das minorias nas companhias. Sem a garantia, a tendência que se apresenta é de desestímulo ao investimento em atividade produtiva e concentração nas aplicações de capital que não tenham relação direta com a produção. É sensível, no mercado, a necessidade de garantir-se uma administração mais participativa, o que pressupõe o resgate do papel das minorias na sociedade anônima. ${ }^{4}$

Outro interessante aspecto de planejamento empresarial, na busca da eficiência, reside no estabelecimento de parcerias estratégicas que podem modificar a composição acionária das companhias garantindo a partilha do poder de controle dentre os parceiros. Estes podem ser internos, acionistas da companhia, ou externos, empresas em relação de dependência, e um dos instrumentos de harmonização dos interesses é previsto, regulado e utilizado de maneira bastante freqüente na prática societária, trata-se do acordo de acionistas.

A idéia que conduzirá o presente artigo é a de reproduzir sinteticamente o panorama atual em que se insere o referido instituto, na perspectiva da reforma normativa operada, sem omitir-se as transformações que estão a operar no cenário empresarial pátrio. A partir da delimitação objetiva do conceito da locução abordarse-á os reflexos de sua adoção, de forma a que se possa concluir sobre a utilidade do acordo de acionistas como instrumento

2 Lei $n^{0} 6.404 / 76$.

3 Lei $n \circ 9.457 / 97$.

4 A recente Lei $n .$. 10.303/01, que produziu alterações na Lei das Sociedades Anônimas, reconhece a mencionada necessidade e segue a tendência de intensificação dos direitos das minorias. Antes mesmo da aprovação do projeto, o mercado de São Paulo, a BOVESPA, antecipou-se ao estabelecer as regras do chamado Novo Mercado estabelecendo desde logo a ampliação de direito da minoria e a restrição à utilização pelas sociedades anônimas de ações preferenciais destituídas do direito de voto, dentre outros aspectos. 
acessório viabilizador de operações e resultados compatíveis com os processos de reestruturação societária e reorganização da economia nacional.

raciocínio exposto cingir-se-á às sociedades constituídas sob a forma do anonimato $^{5}$ em razão de ser a modalidade societária que melhor se adapta à congregação daqueles que pretendem o desenvolvimento da atividade empresarial (empreendedores) e dos que se propõem a investir na atividade produtiva, por meio do fornecimento dos recursos necessários à viabilização do negócio. Será no regime jurídico das S/A que serão encontrados os elementos para os ajustes "parassociais" sob a forma de acordo de acionistas, muito embora, pela própria natureza do instituto, outras questões venham a ser tangenciadas no transcorrer de alguns raciocínios.

\section{Breve panorama do instituto no Direito brasileiro}

Foi a partir da lei de 1976 que o acordo de acionistas recebeu tratamento expresso no direito positivo brasileiro, assim como o fenômeno do controle, indissociavelmente ligado à distribuição de poder no âmbito interno da companhia. Foi na década de setenta que os doutrinadores voltaram seus estudos ao rompimento da dicotomia poder e risco, outrora tão cara ao direito comercial. A aceitação na siste- mática pátria da emissão pelas companhias de até dois terços ${ }^{6}$ de suas ações destituídas do poder de deliberação, nas chamadas ações preferenciais, trouxe ao campo jurídico o reconhecimento da existência de uma categoria de acionistas diversa das tradicionalmente reconhecidas: o acionista investidor. Menos preocupado com a condução da companhia do que com o resultado positivo ao final do exercício, ou, numa segunda fase, com a cotação do preço das ações no mercado mobiliário. Acionistas preferenciais porque titulares de ações que lhes atribuem algumas vantagens em contraposição à perda do direito de voto.

Como decorrência da sistemática, o poder pode estar concentrado em mãos de acionista ou grupo de acionistas que detenha apenas o percentual de ações suficientes para assegurar a maioria dos votos nas deliberações e, especialmente, a indicação da maior parte dos administradores da empresa. ${ }^{7}$ Em outras palavras, consagra-se a possibilidade de o controlador não ser o acionista que mais investiu na sociedade, e, via de conseqüência, o que ostenta os maiores riscos. As alterações consagradas na Lei Societária demonstram o poder de adaptação do direito comercial, e muito especialmente, do direito societário, em face das modificações dos instrumentos e suas necessidades fáticas.

5 Na prática, em sociedades constituídas sob a forma de Sociedades por Quotas de Responsabilidade Limitada, os sócios vêm utilizando-se de pactos parassociais, aos quais a Doutrina tem denominado "Acordo de Quotistas".

6 A Lei no 10.303/01 estabelece novo percentual, de cinqüenta por cento, referente à emissão de ações preferenciais.

7 A Lei de 1976 reconheceu legislativamente a figura do controlador no art. 116 e no seu parágrafo único, destacando a existência de dois elementos: a titularidade da maioria das ações com direito a voto e o efetivo exercício do poder de deliberar e de escolher os administradores. 
A nova concepção de sociedade anônima, pela aceitação da figura do controlador, também conduziu ao incremento da disciplina normativa das formas de controle. $\bigcirc$ titular do poder de direcionamento da empresa não precisa ser um único sujeito de direito - pessoa física ou jurídica mas uma organização de acionistas que, isoladamente, deixariam de ostentar a condição de comando, abrindo espaço ao acordo de acionistas.

Antes da Lei, a doutrina dividia-se em duas grandes vertentes na análise das situações de acordo de acionistas: uma que reconhecia a validade do acordo como negócio jurídico fundado no direito das obrigações, válido dentro do princípio privatista de aceitar como permitido o que a lei não proíbe; outra, que repudiava o pacto porque estar-se-ia a retirar da assembléia sua função institucional de fórum de debates, por permitir o estabelecimento de resoluções prévias dos signatários sobre os temas encaminhados ao debate e deliberação, para esta segunda corrente o pacto poderia ser válido entre as partes do negócio mas não seria oponível à companhia. ${ }^{8}$

A Lei no 6.404 não criou nem definiu o instituto, apenas legalizou-o pelo reconhecimento. Trata-se de um contrato firmado por acionistas de uma mesma companhia. Em razão de suas peculiaridades, tem como fonte primária a Lei societária e secundária o direito das obrigações. No art. 118 da lei do anonimato tem-se a matriz legal do acordo no direito positivo pátrio, mas a validade deste contrato deve estar sempre amparada pelas regras do direito comum aos negócios jurídicos.

$\mathrm{Na}$ sistemática que antecedeu a reforma, a Lei previa a possibilidade de que tais ajustes parassociais versassem, primordialmente, sobre dois objetos: a regulação do exercício do voto e a regulação da negociabilidade das ações. Quando o objeto do acordo enquadrava-se na tipificação, os pactos deveriam ser observados pela companhia e surtiriam efeitos perante terceiros, desde que arquivados na sede da companhia. Certamente que tais acordos não se resumiriam às hipóteses previstas pelo legislador. Ao enumerá-las o legislador não inibiu que se estipulassem outros objetos, mas, valendo-se de situações específicas, disciplinou os seus efeitos em relação à própria sociedade.

Com a reforma, a nova redação do art. 118 consagra a ampliação da utilização destes acordos ao incluir no caput do dispositivo $^{9}$ um novo objeto do pacto que se refere ao exercício do poder de controle. Na redação originária o pacto já poderia estar associado ao exercício do poder de controle, não como objeto, mas efeito do conteúdo do acordo de acionistas. A partir da nova redação abre-se espaço para que o pactuado verse de

8 Cf. BARBI FILHO, Celso. "Acordo de acionistas: panorama atual do instituto no direito brasileiro e propostas para a reforma de sua disciplina legal". In Revista de Direito Bancário, do Mercado de Capitais e da Arbitragem, ano 3, no 8, Ed. RT, abr.-jun./2000, p. 35.

9 A nova redação assim dispõe: "Art. 118. Os acordos de acionistas, sobre a compra e venda de suas ações, preferência para adquiri-las, exercício do direito de voto, ou do poder de controle deverão ser observados pela companhia quando arquivados na sua sede". 
forma específica sobre o exercício do poder de controle, podendo ser registrado e arquivado na companhia, de forma a garantir maior segurança aos signatários e observância pela companhia, que, de qualquer sorte, deverá cumprir o pactuado.

A nova disciplina legal traz o reconhecimento do acordo de acionista como instrumento disciplinador da partilha de poder de controle entre acionistas dispostos a influenciar a condução da empresa, numa nova concepção que permite a associação entre interessados sem a necessidade específica de aumento da quantidade de ações com direito a voto de sua titularidade direta. Também pode, no caso concreto, viabilizar um acordo de transferência ou delegação de poder de controle daquele que pretensamente se enquadraria na previsão do art. 116, em benefício de acionista mais bem estruturado ou apto ao direcionamento da empresa, sem que com isso este último se obrigue a adquirir o montante de ação necessário ao referido enquadramento.

Como se pode observar, a idéia de pacto entre acionistas, propiciado pela utilização do acordo de acionistas, associa-se à sistemática de aceitação do controle no campo das sociedades empresarias.

\section{Natureza jurídica}

A Lei societária propicia que os acionistas de uma mesma companhia componham livremente seus interesses por acordo entre si celebrado, desde que estes não ofendam o ordenamento jurídico ou o estatuto social. Tal possibilidade de composição se compatibiliza com o princípio da livre iniciativa e da autonomia da vontade. Respeitados os parâmetros legais, as forças internas da sociedade comercial podem agir de forma ordenada e da maneira mais adequada à consecução de seus objetivos individuais. Caso, entretanto, versem sobre os temas previstos na Lei e estejam arquivados e averbados na companhia, estarão sujeitos ao regime e à proteção previstos na legislação societária. Vale dizer, ao versarem sobre as hipóteses valoradas pelo legislador, estarão aptos a produzir efeitos mais fortes e abrangentes do que se poderia esperar de um pacto, regido pelo direito comum, que pudesse ser firmado entre sujeitos de direitos capazes e aptos.

Em razão da liberdade de contratar e da extensão dos princípios da livre iniciativa e autonomia da vontade, os contratos entre acionistas poderão versar sobre os mais variados temas de seu interesse, v.g., políticas de administração, formas de eleição para o conselho de administração, preferência para aquisição de ações ou restrições para sua circulação e estipulações concernentes ao voto em assembléia.

A doutrina já se firmou no sentido de admitir que a natureza do acordo de acionista seja de um negócio jurídico orientado pelo preceito do art. 82 do Código Civil (art. 104 da Lei n⿳o 10.406/02 que instituiu o novo Código Civil), contendo declarações de vontade dos sócios sobre direitos e obrigações de sua esfera privada, com um conteúdo distinto das determinações existentes no estatuto social. ${ }^{10}$

10 De modo diverso pensa FÁBIO ULHOA COELHO quando destaca em seu Curso de direito comercial, v. 2, que "em vista de norma legal específica sobre o tema, e das peculiaridades das relações entre sócios de um empreendimento econômico, a 
BARBI FILHO definia-o da seguinte forma: "tem-se que o acordo de acionistas possui a natureza jurídica de negócio jurídico de direito privado, sendo um contrato civil, nominado, parassocial em relação à companhia, preliminar, plurilateral quanto aos interesses que congrega, podendo ser plurilateral, bilateral ou unilateral quanto às obrigações que impõe às partes" . ${ }^{11}$

Temos um pré-contrato porque por intermédio dele as partes prometem firmar contrato definitivo ou emitir declaração de vontade, que se caracterizam pelo fato de terem autonomia formal em relação aos atos constitutivos da sociedade, muito embora, e ao mesmo tempo, apresentem coligação funcional com estes últimos (por isso são ditos parassociais). Evidentemente, o que se estipula não é a venda das ações, mas sim a promessa de fazê-la sob tais e quais condições, o mesmo acontecendo com o exercício do direito de voto e do poder de controle, pois o que se pactua são determinadas metas e critérios a serem obedecidos no exercício destes, seja durante a assembléia, seja diante das situações que envolvem decisões administrativas.

\section{Modalidades de acordo}

Uma leitura atenta do art. 118 desvela que o legislador tipifica quatro espécies de acordo, que, a rigor, podem ser divididos em três gêneros: acordos de voto, acordos de bloqueio e acordos quanto ao exercício do poder de controle. Quando a
Lei diz: "Os acordos de acionistas, sobre a compra e venda de suas ações, preferências para adquiri-las, exercício do direito de voto, ou do poder de controle deverão ser observados pela companhia quando arquivados na sua sede" (grifamos), pretende-se que, contendo o acordo qualquer dos quatro objetos, gere efeitos de obrigatoriedade perante a companhia e terceiros, desde que observados os procedimentos de validade devidos. Assim, muito embora o pacto entre acionista possa ostentar o mais variado conteúdo, para que seja dotado das características diferenciadoras asseguradas pela leioponibilidade em face da sociedade e de terceiros - somente poderá versar sobre os objetos tipificados em lei e deverá obrigatoriamente submeter-se ao arquivamento na sede da companhia, sem que esta tipificação de objetos exclua a possibilidade da existência de pactos ajustando outros objetos, seja de modo acessório, seja de modo autônomo.

No que tem pertinência com a limitação do conteúdo dos ajustes, a Doutrina costuma indicar alguns objetos como sendo ilícitos para comporem os termos dos acordos de acionistas. Poder-se-ia enumerar como sendo as principais restrições que estariam fadadas à caracterização da ilicitude já em razão de seu conteúdo: a) comércio de voto (crime, art. 177, § 2o, CP); b) indefinição da matéria, objeto indefinido, ausência de diretriz; c) acordos que tenham por objeto as declarações de verdade (aprovação de contas); d) viola-

disciplina jurídica do acordo de acionista deve exaurir-se no campo do direito societário, não se justificando o aproveitamento de lições do direito civil relacionadas à evolução do tratamento das obrigações de fazer juridicamente infungíveis". P. 319.

11 BARBI FILHO, Celso. Acordo ..., p. 37. 
ção da legislação antitruste, de proteção à economia popular e aos consumidores; e) acordos danosos ao interesse da sociedade (art. 115 da Lei); f) violação de direitos essenciais do acionista. ${ }^{12}$

que acontecia na prática societária, até por uma questão de cautela e para evitar maiores desarranjos, é que os pactos acabavam versando, via de regra, sobre o acordo de voto (prévio ajuste para o seu exercício) ou sobre o acordo de bloqueio (regras sobre a negociabilidade das ações).$^{13}$ Este foi um dos motivos pelo qual o legislador introduziu nova modalidade consagrada de acordo de acionista ligada ao exercício do poder de controle e que se difere dos ajustes quanto ao voto. $\bigcirc$ acordo de acionistas, de forma diversa à compra ou desvio de voto, propicia ajustes de políticas de administração na seara de direito de controlador e não controladores, podendo ser utilizado como instrumento implementador de uma salutar administração corporativa. Ao contrário dos ajustes espúrios, ocultos ao conhecimento dos eventuais interessados, a sistemática do acordo de acionistas que verse sobre poder de controle determina o seu registro, qual seja, uma forma de publicidade acessível aos interessados que poderão, a partir do conhecimento do teor de tais ajustes, melhor conhecer da realidade da empresa e dos interesses a que está sendo conduzida por meio do estabelecimento de acordo de vontade.
A ampliação do objeto reconhecido como específico de acordo de acionistas pode ser vista como um grande avanço que possibilita ao investidor (tanto ao comum, como ao grande parceiro) ajustar políticas a serem pautadas no exercício do controle de forma clara e acessível aos que detenham interesse na empresa.

A alteração da previsão legal do conteúdo do acordo de acionistas está também calcada na modificação dos mercados, como fenômeno mundial, embora mais recente no Brasil do que nas economias de maior grau de desenvolvimento. Há que se considerar a tendência, reafirmada pelos parâmetros da reforma, de dispersão acionária, importante fator de modificação da composição acionária das Companhias nacionais, passando-se da fase de composição e administração familiar para a de busca de novos parceiros e de profissionalização. Trata-se de uma abertura não apenas em termos de mercado interno, como também mundial, a se seguir a alardeada onda de globalização econômica. Tais perspectivas afetarão - e já estão afetando - a composição acionária das Companhias, de tal modo que os antigos "proprietários" terão que remodelar suas convicções e buscar novas perspectivas por meio de novos parceiros.

Também por esta última ótica, o papel do acordo de acionista ganha destaque.

12 BARBI FILHO, Celso. In Acordo de acionistas. Belo Horizonte: Del Rey, 1993. Apresenta lista um pouco mais extensa e detalhada que merece consulta.

13 BARBI FILHO, Celso. Op. cit., ressalta: "embora tenha ficado evidenciado a não limitação dos objetos do acordo a essas duas modalidades, é inegável que elas são as de maior interesse prático. Além disso, não se pode negar a realidade legal em nosso sistema, que impõe essa limitação ao objeto como requisito de oponibilidade à companhia". P. 98 


\subsection{Acordos sobre o exercício do direito a voto ou de poder de controle}

Diante do atual grau de desenvolvimento das economias modernas e do fortalecimento do ideal liberal no estabelecimento dos sistemas econômicos dos países desenvolvidos ou em desenvolvimento, a aceitação da possibilidade de, no exercício da autonomia privada, os acionistas disporem de sua liberdade individual para estabelecerem condutas e ideais comuns na condução dos negócios empresariais é inevitável. $\bigcirc$ ceticismo inicial que se instalou na doutrina e na jurisprudência, com destaque para a doutrina francesa, neste sentido, principalmente no começo do século XX, encontra-se superado. Chegou-se à correta e definitiva conclusão que qualquer ajuste referente ao direito de voto é inerente à própria liberdade privada existente na esfera das relações patrimoniais dos acionistas.

COMPARATO,${ }^{14}$ com suporte na doutrina alemã, há muito elucidou a questão: "O direito de voto do acionista não se funda em sua personalidade, mas numa fração de sua esfera patrimonial. Ele se mede exatamente, em princípio, pela quantidade ou montante das ações que o seu titular possui, ações essas que representam, por sua vez, unidades-alíquotas do capital da companhia (...). Ora, na esfera das relações patrimoniais, a autonomia privada consiste, justamente, em poder negociar e ceder, livremente, os seus direitos. Se o acionista não é obrigado a comparecer às assembléias gerais, se pode a todo o tempo ceder as suas ações, por que atentaria contra a sua liberdade a estipulação de votar neste ou naquele sentido?".

Com efeito, tais ajustes podem viabilizar uma melhor organização empresarial por meio de prévio ajuste quanto ao sufrágio entre os partícipes da assembléia, evitar surpresas e desconfortos, deixar mais harmônica e, conseqüentemente, menos conflituosa a vida societária, propiciar aos sócios uma maneira lícita de administrar as situações de controle (art. 116), ou, aos não controladores, uma possibilidade de reunir forças na defesa de interesses comuns e específicos.

Muito embora a tônica do trabalho, até o presente momento, tenha se pautado no acordo de acionista de controladores ou com a finalidade de controle, o documento também possibilita a aproximação entre minorias, de forma a viabilizar determinadas deliberações cujo conteúdo está a depender de uma maior participação acionária. Estáse fazendo referência às deliberações previstas na lei e que se condicionam à manifestação, por exemplo, de acionistas que representem $10 \%$ do capital social. $\bigcirc$ pedido de exibição de livros, v.g., pode ser inviável para um acionista isoladamente, a depender do grau de dispersão das ações, mas pode ser viabilizado pela organização das minorias e expresso num acordo neste sentido.

Voltando às situações de controle, é da doutrina de MODESTO CARVA-

14 COMPARATO, Fabio Konder. O poder de controle na Sociedade Anônima. Rio de Janeiro: Forense, 1983, p. 180 e 181. 
$\operatorname{LHOSA}^{15}$ que se extrai a percepção de que podem se dar sob duas condições diversas: a primeira pela qual a "aglutinação de voto das ações dos conventes poderá abranger percentual minoritário de ações que sejam porém suficientes para o exercício do controle (arts. 112 e 116)"; e a segunda e mais comum na qual "poderão somar votos majoritários, o que dará maior estabilidade ao controle; ou até mesmo abranger a totalidade das ações votantes", demonstrando aos parceiros e investidores uma situação de harmonia. Embora ambas possam estar associadas ao estabelecimento de acordo de acionistas, a segunda é dotada de maior estabilidade.

Quanto à limitação dos acordos, em qualquer de suas modalidades, suas estipulações devem ter como paradigma o que diz o art. 115 da Lei das S/A:16 "O acionista deve exercer o direito de voto no interesse da companhia; considerar-se-á abusivo o voto exercido com o fim de causar dano à companhia ou a outros acionistas, ou de obter, para si ou para outrem, vantagem a que não faz jus e de que resulte, ou possa resultar, prejuízo para a companhia ou para outros e acionistas". (grifei)

Certamente o instituto não se destina simplesmente a fazer prevalecer o interesse do controlador. A própria conduta que será imposta à sociedade, pelo controlador, deve levar em consideração o contraponto ao reconhecimento de sua especial condição frente à companhia. $\bigcirc$ parágrafo único do art. 116 é claro ao estabelecer que o controlador deve conduzir a companhia à busca da satisfação dos interesses da empresa, dos demais acionistas, dos empregados e da comunidade onde atua. Logo, ao exercer o poder bastante concentrado que a sistemática jurídica lhe assegura, o controlador e também os administradores da empresa obrigam-se a levar em consideração a imensa gama de interesses que permeiam a atividade de uma empresa e que podem ser sintetizados no interesse da empresa - e de sua preservação , dos demais acionistas - de obter os melhores resultados -, dos empregados - no que diz respeito aos seus padrões de vencimento, por exemplo - e da comunidade onde atua - ao se constatar a influência que o exercício da atividade empresarial produzirá sobre o meio.

Também como contraponto da situação de controle e na medida em que a propriedade das ações de uma companhia encontra-se cada vez mais dispersa, ${ }^{17}$ viabiliza-se outra hipótese em que se tutela o interesse da minoria, são os denominados acordos de defesa. Neste caso, os acionistas que não têm o controle da companhia organizam sua posição, seja para opor-se aos controladores, seja apenas para fiscalizar eficazmente a legalidade e legitimidade dos atos por eles praticados. A mesma lógica que fez admitir os acordos de controle poderá ser invocada na hipótese.

Pode-se concluir que os acordos de voto podem ser ou de comando (manutenção ou arranjo de situação de controle, art.

15 Vide CARVALHOSA, Modesto. Op. cit., p. 469.

16 Eis que as matérias convencionadas para o voto, via de regra, fazem parte das deliberações em assembléia.

17 O fenômeno da dispersão acionária pode ser verificado tanto em companhias abertas como em fechadas. 
116) ou de defesa, no qual determinado grupo de não controladores se une com o intuito de conquistar percentuais mínimos que possibilitem exercício de direitos de forma coesa, conforme já mencionado e que pode ser verificado nas hipóteses legais extraídas dos arts. 105, 123, 124, 133, 141, 157 e 161 da Lei do anonimato.

Outro mecanismo de ajuste que vem sendo muito utilizado refere-se ao poder de veto. ${ }^{18} \mathrm{O}$ veto, como tem sido chamado, ocorre apenas no âmbito interno do acordo e decorre da livre manifestação do acionista com maior número de votos, o qual condiciona sua votação à aceitação do outro signatário que não teria condições de impedir a aprovação de determinadas matérias. $\mathrm{O}$ voto do acionista que em princípio não teria grande relevância no âmbito decisório ganha peso de ouro na medida em que - mediante acordo de vontades - determinará a decisão a ser tomada pelo cosignatário de grande poder em termos de decisão. Sobre os inconvenientes do recente mecanismo de contratação do voto, destaca-se a percepção de BARBI FILHO: "as partes só podem votar uniformemente em determinadas matérias ou então reproválas. A conseqüência disso é que, estabelecido um status quo quando da celebração do acordo, uma das partes sempre poderá vetar qualquer mudança na sociedade, criando autêntica ditadura da minoria dentro do acordo". ${ }^{19}$
Mais uma vez cabe a ressalva, como já exposto anteriormente, quanto à vedação de qualquer espécie de comércio de votos ou estipulação sem objetos definidos. Restrição ao conteúdo do acordo é, então, a barganha de benefícios com os controladores, sendo oportuno uma abordagem específica do conteúdo dos acordos de bloqueio.

\subsection{Acordos de bloqueio}

Já consolidados em termos jurisprudenciais e doutrinários são os chamados acordos de bloqueio. Por sua utilização, possibilita-se restrição à disponibilidade patrimonial do acionista signatário da avença. MODESTO CARVALHOSA ${ }^{20}$ apresenta a seguinte definição: "o acordo de bloqueio é um contrato pelo qual o acionista obriga-se, perante um ou mais sócios, a não alienar suas ações, sem o consentimento destes, ou sem renúncia dos mesmos ao direito de preferência, nele estabelecido", COMPARATO ${ }^{21}$ complementa: "Em qualquer hipótese, as estipulações concernentes ao voto em assembléia costumam ser contempladas com restrições à circulação das ações, instituindo-se o que a doutrina européia denominou sindicatos de bloqueio. É por meio destas convenções, portanto, que se regulamenta a compra e venda das ações do signatário ou o exercício do direito de preferência para adquirilas". BARBI FILHO'22 arremata: "idéia

18 Sobre o tema: SALOMÃO FILHO, Calixto, na obra O Novo Direito Societário. São Paulo: Malheiros, 1999, p. 160-168.

19 Op. cit., p. 44.

20 CARVALHOSA, Modesto. Op. cit., p. 141.

21 COMPARATO, Fábio Konder. Op. cit., p. 33.

22 BARBI FILHO, Celso. Acordo de acionistas, p. 112. 
básica a ser observada quando se estuda o acordo de bloqueio é a de que, em princípio, ninguém pode ser obrigado a comprar ou vender ações. $\bigcirc$ que se pode pactuar são as condições em que a compra ou a venda deve se processar, no que se refere a aspectos como preferência em iguais condições, consentimento, opção, forma de pagamento, cessão do direito de preferência e etc.".

É imprescindível ter em mente que, em suma, o que se pactua não é a vedação ou impedimento à circulação das ações dos signatários, mas sim as condições pelas quais tal deva ocorrer, possibilitando maior estabilidade na estrutura da sociedade e propiciando a manutenção das proporções acionárias tal como no momento da avença.

O bloqueio, como pacto autônomo, evitará alterações na participação acionária dos signatários, v.g., restringindo a entrada de estranhos na sociedade ou evitando a alteração do equilíbrio de poder entre os grupos de acionistas. Noutra hipótese, sendo acessório à convenção de voto, figurará com cláusulas que irão restringir a transferência de titularidade de ações que possam obstruir a efetividade do pacto de voto, constituindo impedimento à transferência das ações para terceiros não obrigados, que se furtariam do contratado.

Também expressiva a importância de se operar com acordos de bloqueio numa sociedade anônima.

\section{Conclusões}

A possibilidade de diversificação do objeto dos acordos é das mais amplas, condicionando-se à liberdade das partes e à diversidade de situações que se operam no dia-a-dia da vida de uma sociedade. Todavia, dentro dessas modalidades observadas pelos doutrinadores $^{23}$ deve estabelecer-se sempre a possibilidade de análise da licitude no caso concreto, objetivando sempre a predominância dos interesses da companhia e não dos meros interesses individuais do acionista.

Em qualquer de suas modalidades, o acordo de acionistas, há de se concluir, ainda que diante da brevidade do estudo proposto, revela-se, além de um instrumento de manifestação de vontade individual, ao vincular-se às manifestações de controle, um meio de implementação de práticas administrativas e de condução da empresa posto em harmonia com alguns dos outros valores indissociáveis da prática econômica e que permitirão o estabelecimento de uma situação de suficiente harmonia interna da empresa que possa assegurar a sua longevidade e o maior proveito social.

Quando dissociado do controle, propicia às minorias condições de interferência na vida societária e um estímulo à integração.

Na hipótese de utilização em sua modalidade de bloqueio, transfigura-se em instrumento apto a garantir estabilidade no quadro acionário, de maneira a tornar eficaz, por períodos mais significativos, as decisões tomadas pelos signatários.

23 CARVALHOSA, Modesto. Op. cit., p. 147: Valendo-se de aspectos práticos, o Mestre paulista identifica quatro espécies de ajustes restritivos da negociabilidade das ações: os que exigem preferência na venda de ações; os que estabelecem direito de opção; os que submetem a alienação das ações a prévio consentimento e os que impõe exigências de atendimento a determinadas condições. 
Mais ainda, a idéia de parceria como elemento propulsor dos pactos está em absoluta consonância com os rumos da economia nacional e mundial e com o natural afastamento da noção de uma sociedade anônima pequena, fechada e familiar, substituída pela empresa cujo capital é cada vez mais disperso no mercado, a administração profissionalizada e as finalidades transcendentes aos objetivos egoísticos de um acionista ou grupo restrito.

Como se vê, a perspectiva para os acordos de acionistas é de ostentarem uma posição cada vez mais importante e uma utilização constante nas sociedades contemporâneas.

\section{Referências bibliográficas}

BARBI FILHO, Celso. Acordo de acionista. Belo Horizonte: Del Rey, 1993.
. "Acordo de acionistas: Panorama atual do instituto no direito brasileiro e propostas para a reforma de sua disciplina legal". In Revista de Direito Bancário, do Mercado de Capitais e da Arbitragem, nำ 8, São Paulo: Revista dos Tribunais, abr.-jun./2000.

CARVALHOSA, Modesto. Acordo de acionistas. 1. ed., São Paulo: Saraiva, 1984.

. Comentários à Lei de Sociedades Anônimas. Vol. 2, 2. ed., São Paulo: Saraiva, 1998.

COELHO, Fábio Ulhoa. Curso de direito comercial. Vol. 2, 5. ed., São Paulo: Saraiva, 2002.

COMPARATO, Fábio Konder. "Acordo de acionistas e interpretação do art. 118 da Lei das S/A". In Revista dos Tribunais, vol. 527, São Paulo, 1979.

. O Poder de controle na sociedade anônima. 3. ed., Rio de Janeiro: Forense, 1983.

PEREIRA, Caio Mario da Silva. Instituições de direito civil. Vol. II, 8. ed., Rio de Janeiro: Forense, 1986.

SALOMÃO FILHO, Calixto. Onovo direito societário. São Paulo: Malheiros Editores, 1998. 